\title{
EFFECT OF WIND TURBINE ON TLP FLOATING PLATFORM RESPONSES
}

\author{
Yeshwant Prabhu Chodnekar ${ }^{1}$, Sukomal Mandal ${ }^{2}$, Balakrishna Rao K ${ }^{3}$ \\ ${ }^{1}$ M.Tech (Structures) student, Department of Civil Engineering, Manipal Institute of Technology, Karnataka, India \\ ${ }^{2}$ Retd. Chief \& Head, Ocean Engineering Division, CSIR - National Institute of Oceanography, Goa, India \\ ${ }^{3}$ Professor, Department of Civil Engineering, Manipal Institute of Technology, Karnataka, India
}

\begin{abstract}
Ever increasing population of India demands high production of electrical energy which puts immense pressure on our limited stock of non-renewable sources of energy and makes us dependent over imports from foreign countries. The present study focuses on the innovative concept of renewable offshore wind energy wherein the hydrodynamic analysis of Tension Leg Platform (TLP) Floating Offshore Wind Turbine (FOWT) which supports 5MW wind turbine tower is carried out using 'ANSYS Workbench 14.5'. The six degree responses of the structure are obtained in operational conditions considering rated wind velocity of $11.4 \mathrm{~m} / \mathrm{s}$ in an irregular wave environment. Two cases are mainly considered, the first-one with incident wave and wind combined action along $O^{\circ}$ (case 1) and the second-one with incident wave and wind combined action along $45^{\circ}$ (case 2). The effect of wind turbine on $T L P$ responses is compared in between 10 different geometric models; 5 models ( $A$ ', $B$ ', $\left.C^{\prime}, D^{\prime}, E^{\prime}\right)$ considering only the TLP platform and 5 models $(A, B, C, D, E)$ considering the same platforms along with wind turbine tower. It is observed that TLP FOWT has higher translational motions (surge, sway, and heave) as compared to rotational motions (roll, pitch, and yaw). The metacentric height improves drastically after adding weight to concrete ballast. Higher reserve buoyancy helps reduce surge, sway, roll and yaw. The direction of the incident wave and wind does not affect heave response and remains same when incident wave and wind acts at $0^{\circ}$ or $45^{\circ}$. Higher reserve buoyancy increases pitch response only when incident wave and wind is acting at $0^{\circ}$ but the reverse effect is observed when incident wave and wind is acting at $45^{\circ}$.
\end{abstract}

Keywords: TLP, floating offshore wind turbine, hydrodynamic analysis.

\section{INTRODUCTION}

The demand of electrical energy is getting higher around the world every other passing day and India is no such exception. With limited non-renewable resources of energy (mainly coal) to generate electricity, [1] mentions that over the recent years, India is slowly shifting its focus towards renewable resources of energy like solar and wind to produce electricity. As far as tapping and generating electricity from the wind is concerned, one would really wonder why to go offshore and complicate things when tapping wind energy is fairly simple onshore? [2] and [3] give the answer to this curious question while mentioning the biggest advantage being uninterrupted and constant high efficiency of tapping wind energy as compared to onshore. Since then, this topic has been very intriguing and challenging for researchers to develop new and efficient methods of designing platform to support offshore wind turbines.

[4] gives literature survey of various different Floating Offshore Wind Turbine (FOWT) concepts that are being researched at present around the world. Previously, many researchers took the challenge to develop a mechanism to analyse FOWT considering NREL (National Renewable Energy Laboratory) 5MW baseline wind turbine developed by [5]. [6] made the first to attempt analysis of Tension Leg Platform (TLP) type FOWT concept considering it as a fully coupled dynamic system. Later, [7] continued his work and showed that tension-legged mooring system is soft in surge and sway but stiff in rotational modes whereas taut-leg mooring system was stiff in surge and sway and soft in rotational modes. [8], presented a collaborative research done by Massachusetts Institute of Technology (MIT) and NREL which compared the responses of a TLP and a Shallow Drafted Barge (SDB) type of FOWT and showed that dynamic response of both the concepts were favourable but the cost of constructing SDB was $28.4 \%$ higher than TLP. Considering the limitations of previous time and frequency domain studies of FOWT, [9] made an attempt to develop a simulation and modelling technique for fully coupled aero-hydro-servo-elastic response. [10] and [11] compared TLP, barge and spar-buoy type FOWT and showed that barge type is more susceptible to roll and pitch motions and consequently transfers higher loads to wind turbine. The roll and pitch motions of spar type were greater than TLP but was more stable in yaw than TLP. [12] carried out analysis and compared various FOWT concepts like TLP, spar, barge and semi-submersible and showed that TLP experienced least loads amongst others. [13] carried out analysis on fixed monopile foundation and other FOWT concepts like spar, barge and semi-submersible type, supporting NREL 5MW wind turbine and found that semisubmersible has better stability in surge than barge type; spar is stable in pitch and heave than barge and semisubmersible and semi-submersible has higher pitch than barge but surge, sway, roll and yaw motions are lesser than 
barge. Besides this an interesting thing that is observed is that surge and pitch increases until wind is $12 \mathrm{~m} / \mathrm{s}$ and decreases for $24 \mathrm{~m} / \mathrm{s}$ due to blade-pitch controller action of wind turbine. [14], showed that by using space-frame in wave action zone of FOWT wave and anchor loads can be reduced. It would really be interesting to see if researchers merge this concept with [15] and [16] to come up with an innovative FOWT concept. [17] reported few of the FOWT concepts that have been actually commissioned offshore and also highlights various others that are under development mainly in Europe and USA region. MIT/NREL TLP was improvised by [18] and named it as South China Sea (SCSTLP) to show that the improvised SCS-TLP was stable in both operational and extreme conditions but needed more improvement in yaw motion. It is also suggested that increasing the length of the spokes might improve the yaw response but needs more research. Later, [19] proposed a HIT-FOWT-TLP which has $49 \%$ displacement and $27 \%$ mass as compared to NREL-TLP from [8]. [20] gives a comprehensive research and design of TLP as FOWT using new developed conceptual tool called 'SIMO-RIFLEXAeroDyn' which shows that response of FOWT motions is inversely proportional to the amount of water displaced. It is also mentioned that yaw and roll natural periods can be lowered by increasing the spoke/pontoon size.

\section{MODELLING}

The models presented in this paper are inspired from SCSTLP developed by [18]. The model basically consists of a main steel spar buoy with concrete ballast attached externally at the bottom and has four radiating spokes at a distance of $8 \mathrm{~m}$ from top of the concrete ballast. It is chamfered at top to minimize loads due to wave action. Fig 1 shows the TLP FOWT (model A) with the wind turbine tower. The rotor and the nacelle of the wind turbine are modelled as lumped mass at a hub height of $90 \mathrm{~m}$. Fig -2 shows the TLP platform over which the wind turbine is placed (model A').

Table 1 shows the various geometric models that are modelled using ANSYS Design Modeler. Models A', B', C', D' \& E' are modelled considering only the TLP platform and models A, B, C, D \& E are modelled considering the TLP platform with wind turbine. The tension-legged mooring cable is connected at the end of each spoke and anchored to sea bed at a water depth of $200 \mathrm{~m}$. The combined linear stiffness of the single mooring cable is considered as $10^{8} \mathrm{~N} / \mathrm{m}$ and is constant for all the cables of the various geometric models. Freeboard of $10 \mathrm{~m}$ is maintained constant for all the geometric models. ANSYS Mechanical Model module is used to read the data from ANSYS Design Modeller to obtain mass properties and center of gravity location, which are later used in ANSYS Hydrodynamic Diffraction module. Using the output from diffraction module, hydrodynamic time response analysis is carried out.

\section{ENVIRONMENTAL LOADS \& ANALYSIS}

Generally, the wave and wind data are gathered from the site which is favourable for commissioning FOWT in sea and later analysis and design is carried out. In present study, the responses of the TLP FOWT are studied considering the combined wave and wind action under operational conditions considering two cases i.e. case 1 and case 2 with incident wave and wind at $0^{\circ}$ and $45^{\circ}$ respectively wherein which the loads on TLP FOWT are simulated for 800 seconds.

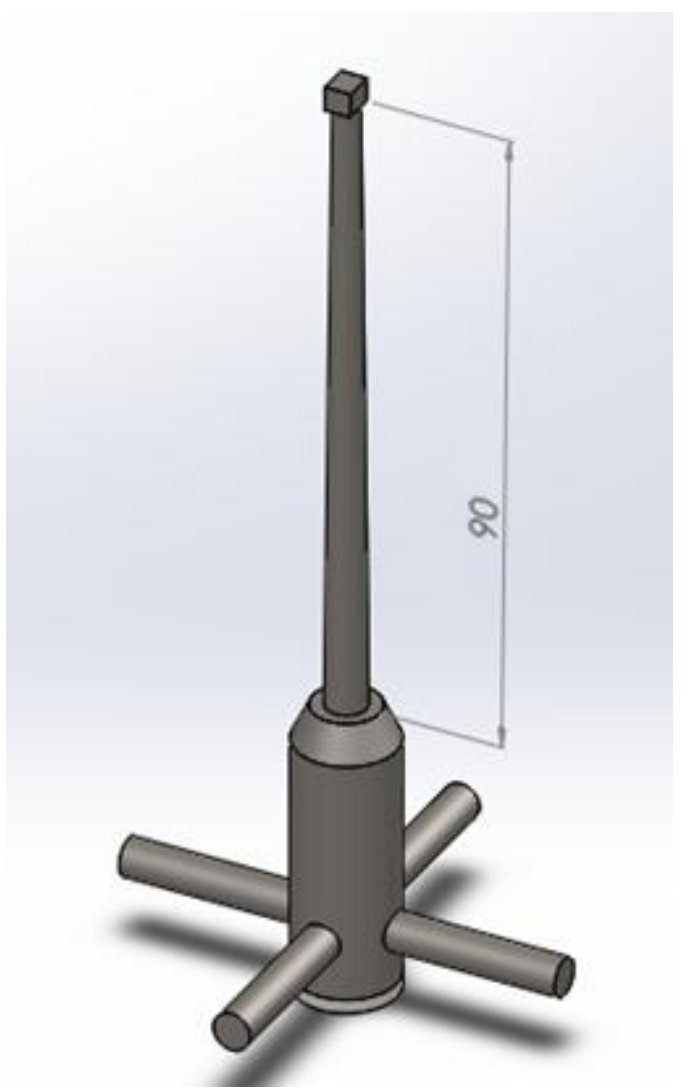

Fig -1: TLP platform (model A) with wind turbine tower (all dimensions in $\mathrm{m}$ )

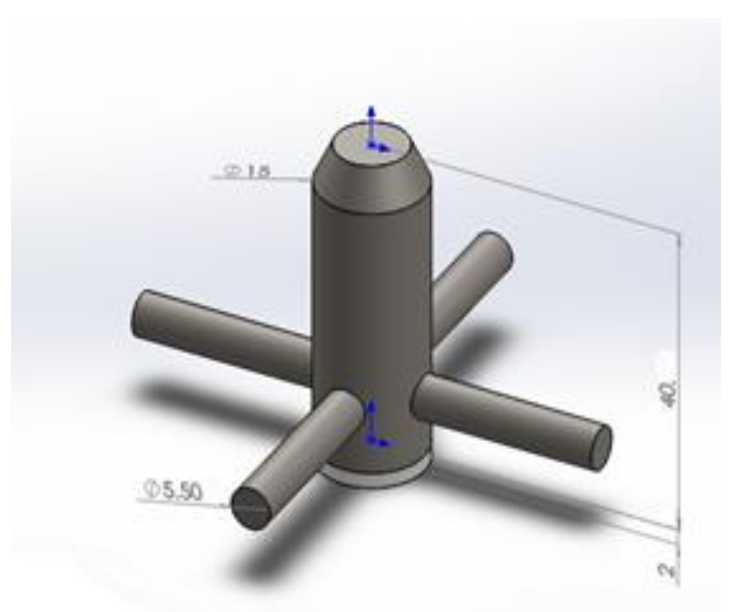

Fig -2: TLP platform (model A') (all dimensions in $\mathrm{m}$ ) 
Figs $-3 a \& 3 b$ show the top view of the TLP FOWT in XY. The $\mathrm{X}$-axis is shown in red colour, the y-axis is shown in green colour and the z-axis in blue colour. Fig -3a shows case 1 with incident wave and wind at $0^{0}$ (as pointed by arrow) and Fig -3b shows case 2 with incident wave and wind at $45^{\circ}$ (as pointed by arrow). The wave and wind action is assumed to act along same direction with no misalignment.

Table -1: Geometric models

\begin{tabular}{|c|c|c|c|c|c|}
\hline $\begin{array}{l}\text { Model } \\
\text { (TLP } \\
\text { wind } \\
\text { turbine / } \\
\text { TLP only) }\end{array}$ & 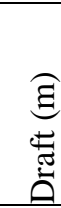 & $\begin{array}{l}\overparen{\Xi} \\
\dot{ \pm} \\
\stackrel{ \pm}{\Xi} \\
. \overline{0}\end{array}$ & 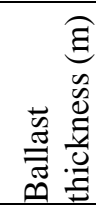 & 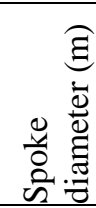 & 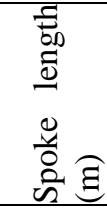 \\
\hline $\mathrm{A} / \mathrm{A}^{\prime}$ & 30 & 15 & 2 & 5.5 & 25 \\
\hline B / B' & 30 & 20 & 2 & 5.5 & 22.5 \\
\hline $\mathrm{C} / \mathrm{C}^{\prime}$ & 30 & 25 & 2 & 5.5 & 20 \\
\hline $\mathrm{D} / \mathrm{D}{ }^{\prime}$ & 20 & 25 & 4 & 5.5 & 20 \\
\hline $\mathrm{E} / \mathrm{E}^{\prime}$ & 20 & 20 & 4 & 5.5 & 22.5 \\
\hline
\end{tabular}

Table -2: Variation of reserve buoyancy

\begin{tabular}{|c|c|c|c|}
\hline Model & 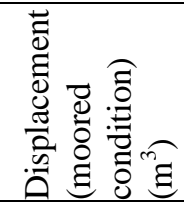 & 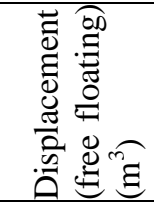 & 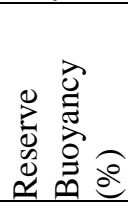 \\
\hline A & 8000.36 & 2850.46 & $64.4 \%$ \\
\hline B & 12160.10 & 3722.09 & $69.4 \%$ \\
\hline $\mathrm{C}$ & 17576.83 & 4798.61 & $72.7 \%$ \\
\hline D & 13657.78 & 6716.36 & $50.8 \%$ \\
\hline $\mathrm{E}$ & 9654.65 & 4904.04 & $49.2 \%$ \\
\hline $\mathrm{A}^{\prime}$ & 8000.37 & 2185.38 & $72.7 \%$ \\
\hline $\mathrm{B}^{\prime}$ & 12160.12 & 3057.02 & $74.9 \%$ \\
\hline $\mathrm{C}^{\prime}$ & 17576.84 & 4133.54 & $76.5 \%$ \\
\hline $\mathrm{D}^{\prime}$ & 13657.80 & 6051.29 & $55.7 \%$ \\
\hline$E^{\prime}$ & 9654.65 & 4238.97 & $56.1 \%$ \\
\hline
\end{tabular}

Table -3: Variation of metacentric height

\begin{tabular}{|l|l|l|l|}
\hline Model & $\begin{array}{l}\text { Center of } \\
\text { Gravity }(\mathrm{m})\end{array}$ & $\begin{array}{l}\text { Center of } \\
\text { Buoyancy } \\
(\mathrm{m})\end{array}$ & $\begin{array}{l}\text { Metacentric } \\
\text { Height }(\mathrm{m})\end{array}$ \\
\hline A & 0.86 & -17.78 & -18.34 \\
\hline B & -5.02 & -17.06 & -11.39 \\
\hline C & -9.50 & -16.65 & -6.06 \\
\hline D & -8.98 & -12.00 & -1.62 \\
\hline E & -5.01 & -12.00 & -6.17 \\
\hline A $^{\prime}$ & -21.42 & -17.78 & 3.94 \\
\hline$B^{\prime}$ & -22.23 & -17.06 & 5.82 \\
\hline$C^{\prime}$ & -22.95 & -16.65 & 7.38 \\
\hline$D^{\prime}$ & -18.11 & -12.00 & 7.51 \\
\hline$E^{\prime}$ & -17.42 & -12.00 & 6.23 \\
\hline
\end{tabular}

\subsection{Wave Loads}

The irregular waves incident to the TLP FOWT are defined by Pierson-Moskowitz spectrum as per DNV-OS-J101 and DNV-RP-C205 offshore standards. The responses of the TLP FOWT are studied under operational conditions assuming the wave height of $3 \mathrm{~m}$ with zero crossing period of 4.25 seconds. The waves of period in between 3 to 12 seconds are considered wherein the responses of TLP FOWT is obtained using diffraction theory.

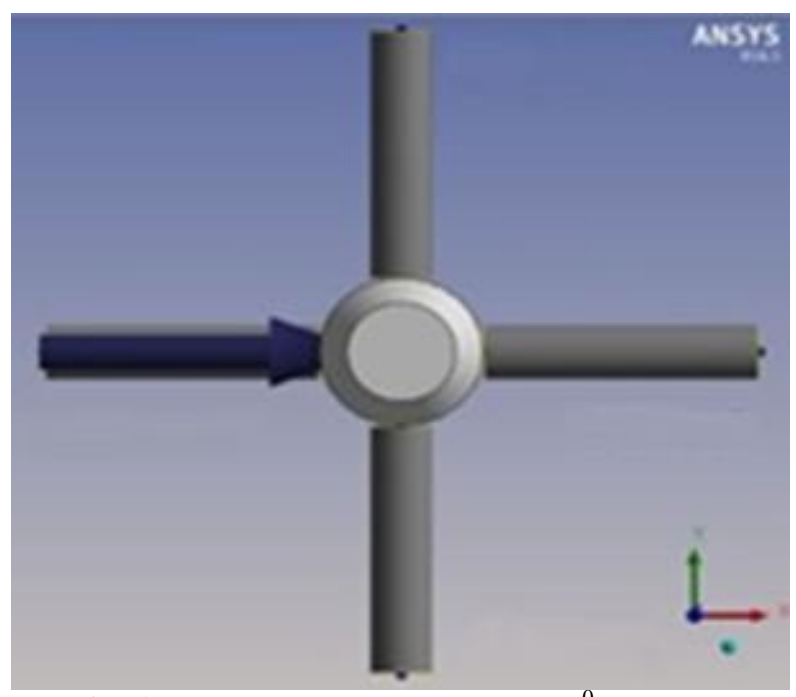

Fig -3a: Incident wave and wind at $0^{\circ}$. (Case 1)

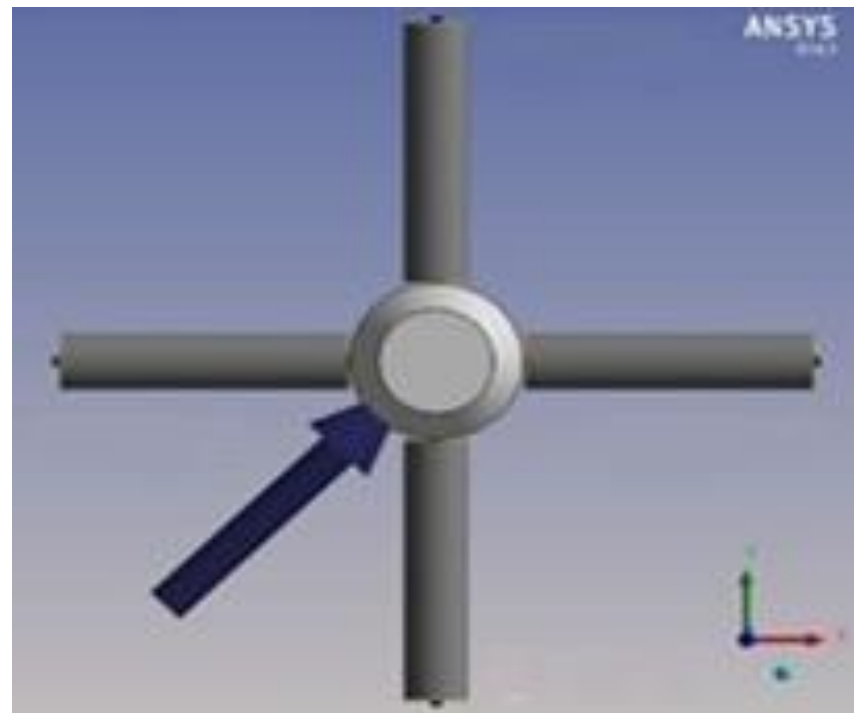

Fig -3b: Incident wave and wind at $45^{\circ}$. (Case 2)

\subsection{Wind Loads}

The wind load on the tower supporting the lumped mass is calculated by considering a constant wind velocity of $11.4 \mathrm{~m} / \mathrm{s}$ at $10 \mathrm{~m}$ height above sea level, which is assumed to be unidirectional and uniform with height. The aerodynamic thrust generated by NREL 5MW wind turbine is considered as a point load at the lumped mass at the top of the wind turbine as mentioned by [23] for operating conditions. 


\section{RESULTS}

After the hydrodynamic analysis is carried out the responses in six degree of freedom system are obtained [translation motion in $X$-axis (surge), translation motion in $Y$-axis (sway), translation motion in Z-axis (heave), rotational motion about $X$-axis (roll), rotational motion about $Y$-axis (pitch), rotational motion about Z-axis (yaw)] for all the geometric models. Table -2 shows variation in reserve buoyancy for all the geometric models. It is observed that as the diameter increases the reserve buoyancy is also increases. Model $\mathrm{E}$ has the least reserve buoyancy and model $\mathrm{C}$ has the maximum reserve buoyancy. Table -3 shows the variation in metacentric height. It is observed that the metacentric height improves drastically as the center of gravity approaches center of buoyancy by increasing the ballast weight. The negative value of metacentric height for geometric models supporting wind turbine tower $(\mathrm{A}, \mathrm{B}, \mathrm{C}$, $\mathrm{D} \& \mathrm{E})$ show unstable equilibrium and need the help of mooring lines to achieve stability. Models having positive value of metacentric height (A', B', C', D' \& E') do not need mooring line to achieve stability and hence can be easily towed from construction site to the wind farm commissioning site.

Figs $-4 a$ and $4 b$ show the peak surge responses for case 1 and case 2 respectively. It is observed that as the reserve buoyancy increases the value of peak surge decreases. Incident wave and wind direction of $0^{\circ}$ has more effect than $45^{\circ}$. When the tower is not placed on the TLP platform, the surge response remains almost equidistant from $y$-axis but when wind turbine tower is placed the surge response mainly undergoes along positive $\mathrm{x}$-axis direction.

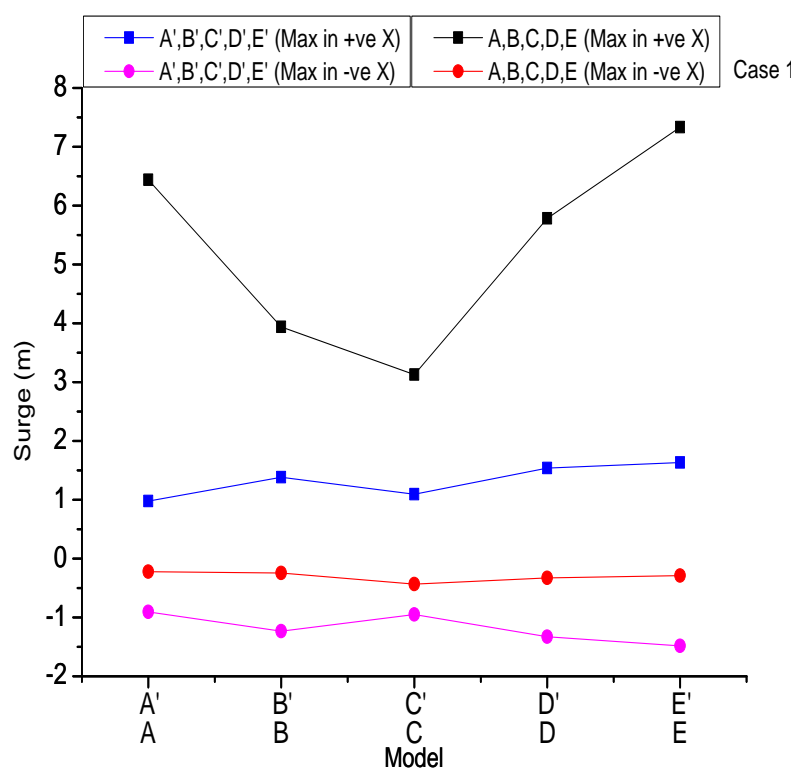

Fig -4a: Peak surge response (case 1)

Fig $-5 \mathrm{a}$ and $5 \mathrm{~b}$ shows the peak sway responses. It is observed that sway response is negligible for case 1 than case 2 respectively. The sway response of case 2 is almost equal to surge response of case 2 .
Fig $-6 a$ and $6 b$ show peak heave responses for case 1 and case 2 respectively. It is observed that due to higher reserve buoyancy the models which considered only the TLP platform (A', B', C', D' \& E') have higher peak heave response as compared to models considering TLP with wind turbine tower (A, B, C, D \& E). Model C with highest reserve buoyancy showed maximum heave response while model E with least reserve buoyancy showed least value of heave response. The direction of the incident wave and wind does not affect peak heave responses and remains same for both the cases.

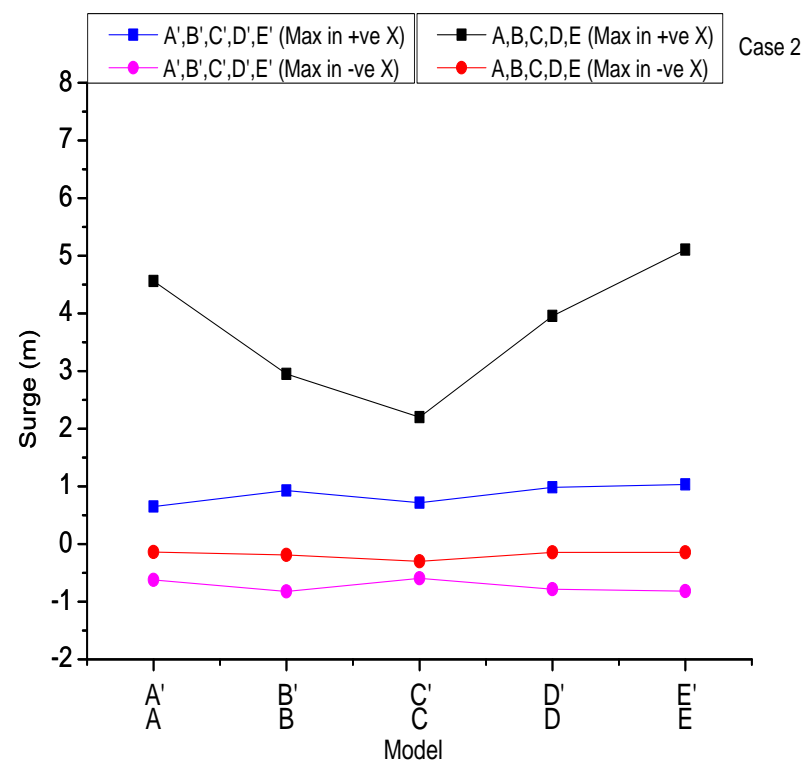

Fig -4b: Peak surge response (case 2)

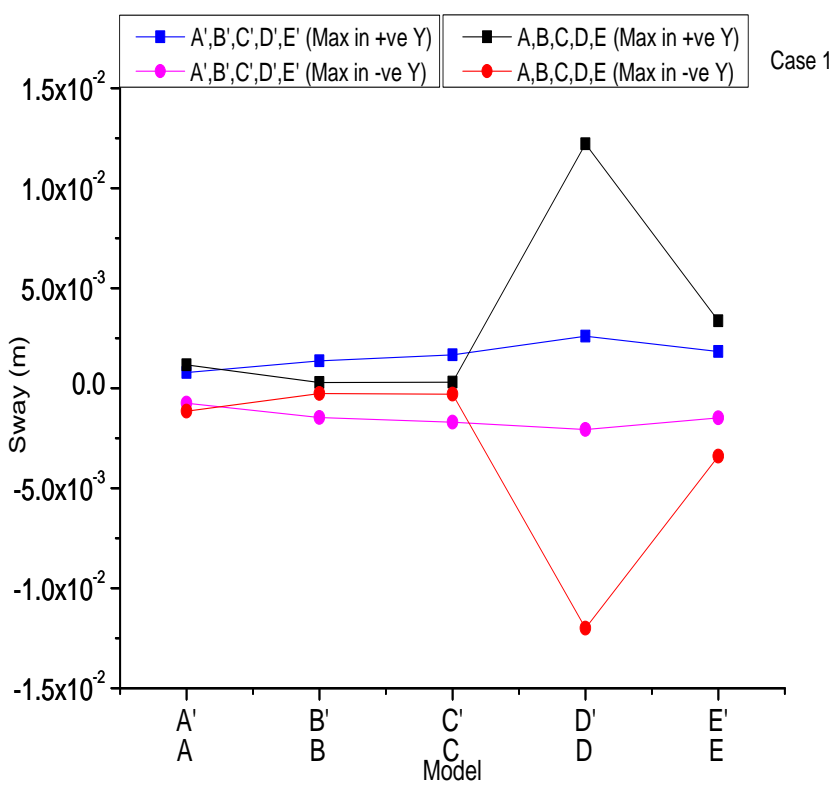

Fig -5a: Peak sway response (case 1) 


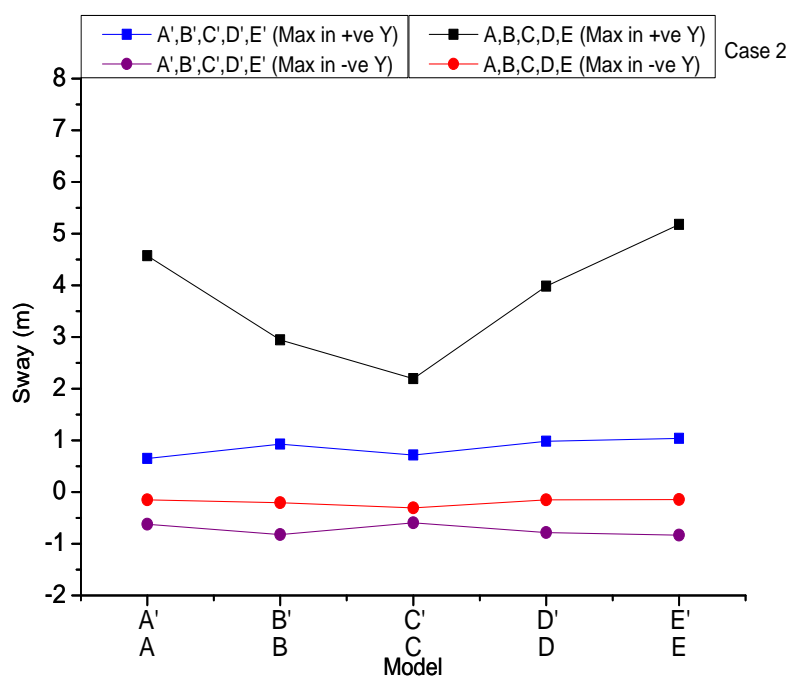

Fig -5b: Peak sway response (case 2)

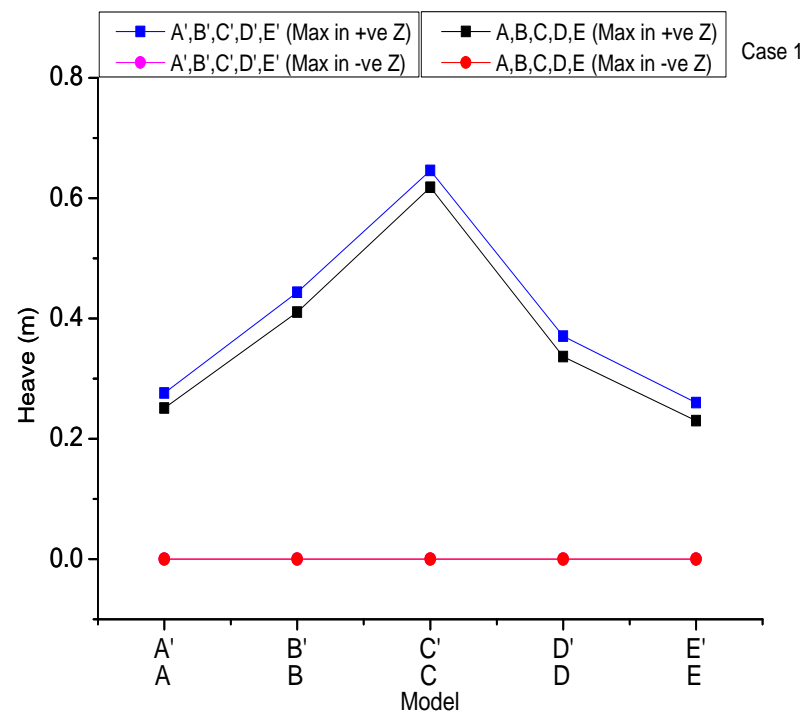

Fig -6a: Peak heave response (case 1)

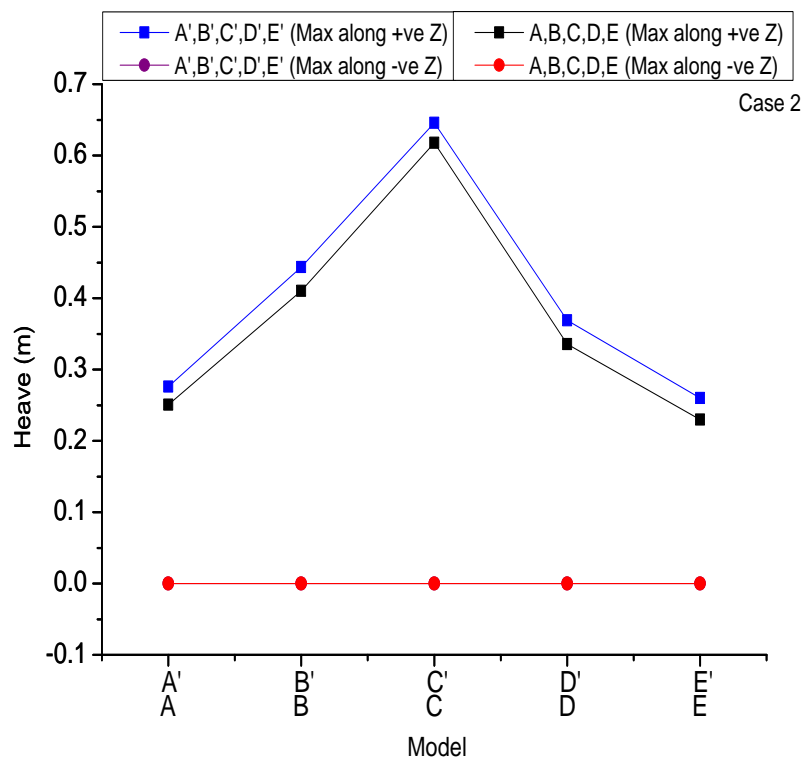

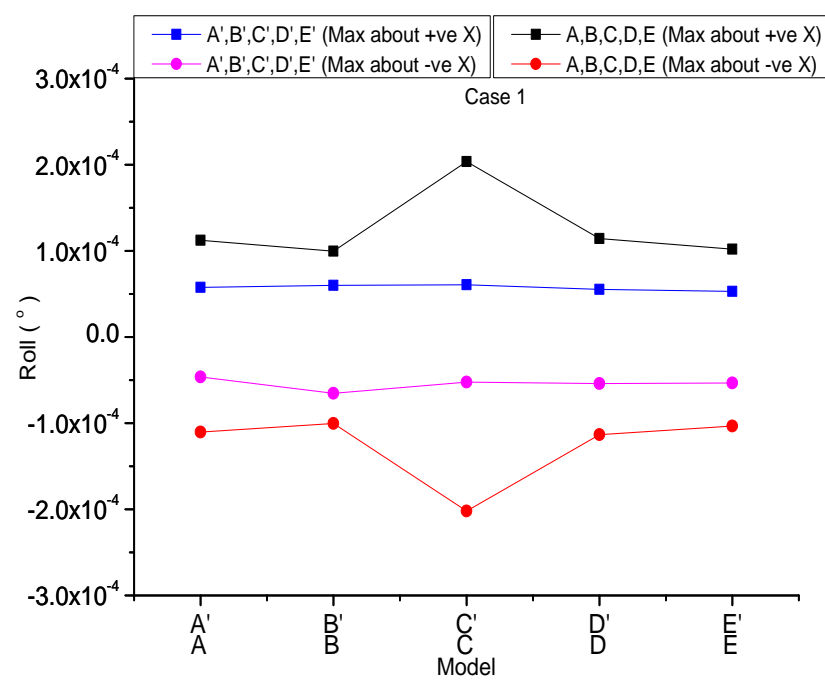

Fig -7a: Peak roll response (case 1)

Fig $-7 \mathrm{a}$ and $7 \mathrm{~b}$ show peak roll responses. It is observed that the roll responses are very much negligible for case 1 as compared to case 2 . Considering only Fig $-7 \mathrm{~b}$ it is seen that lower reserve buoyancy increases roll response. Model $\mathrm{E}$ with lowest reserve buoyancy showed highest value of peak roll.

Fig $-8 \mathrm{a}$ and $8 \mathrm{~b}$ show peak pitch responses respectively. It is seen that higher reserve buoyancy increases the peak roll responses only for case 1 but the reverse effect is observed for case 2. Model C shows highest value of peak pitch response considering case 1 while model $\mathrm{E}$ shows the highest value of peak pitch response considering case 2 .

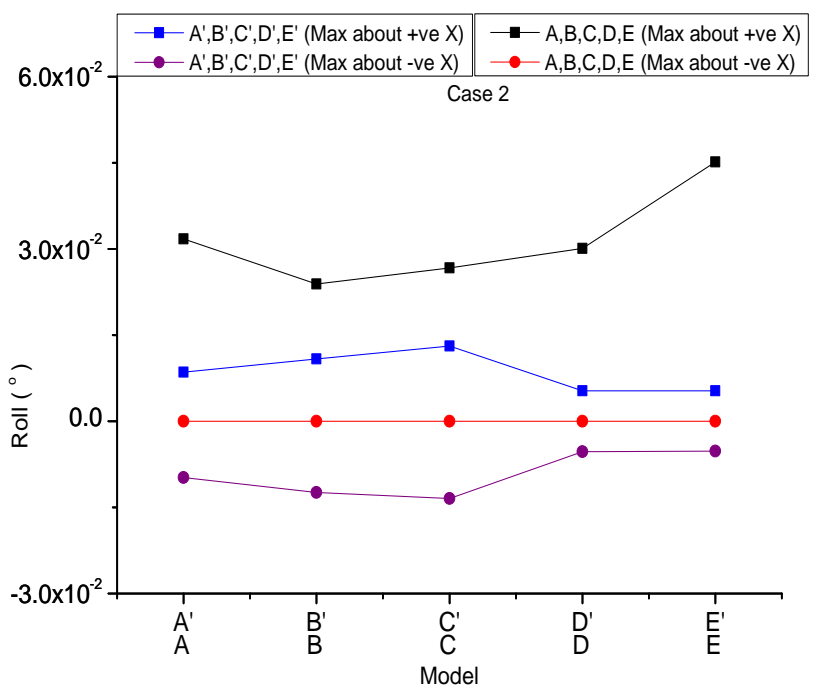

Fig -7b: Peak roll response (case 2)

Fig -6b: Peak heave response (case 2) 


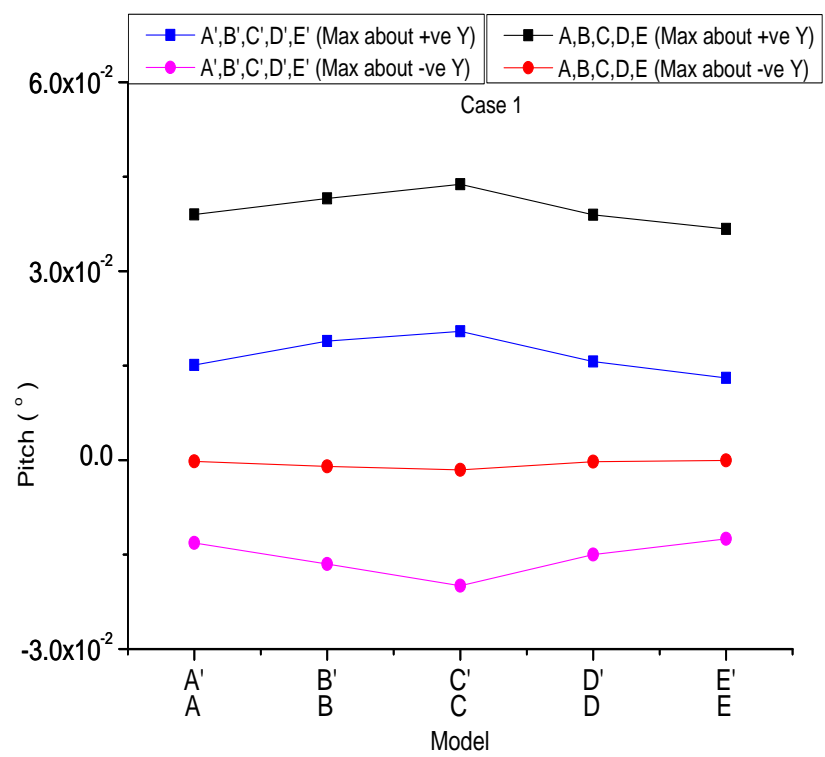

Fig -8a: Peak pitch response (case 1)

Fig $-9 \mathrm{a}$ and $9 \mathrm{~b}$ show the peak yaw responses for case 1 and case 2 respectively. It is seen that the yaw responses are negligible for case 1 than case 2 . Considering case 2 it is observed that higher reserve buoyancy helps reduce yaw responses. Model $\mathrm{C}$ with highest reserve buoyancy shows lowest yaw response while model $\mathrm{E}$ with lowest reserve buoyancy showed highest yaw response.

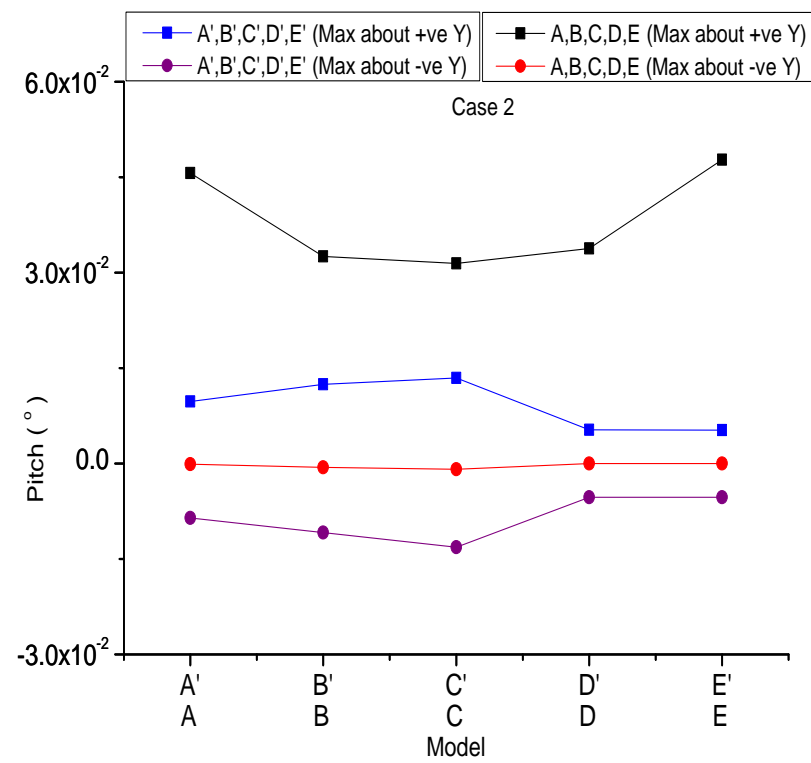

Fig -8b: Peak pitch response (case 2)

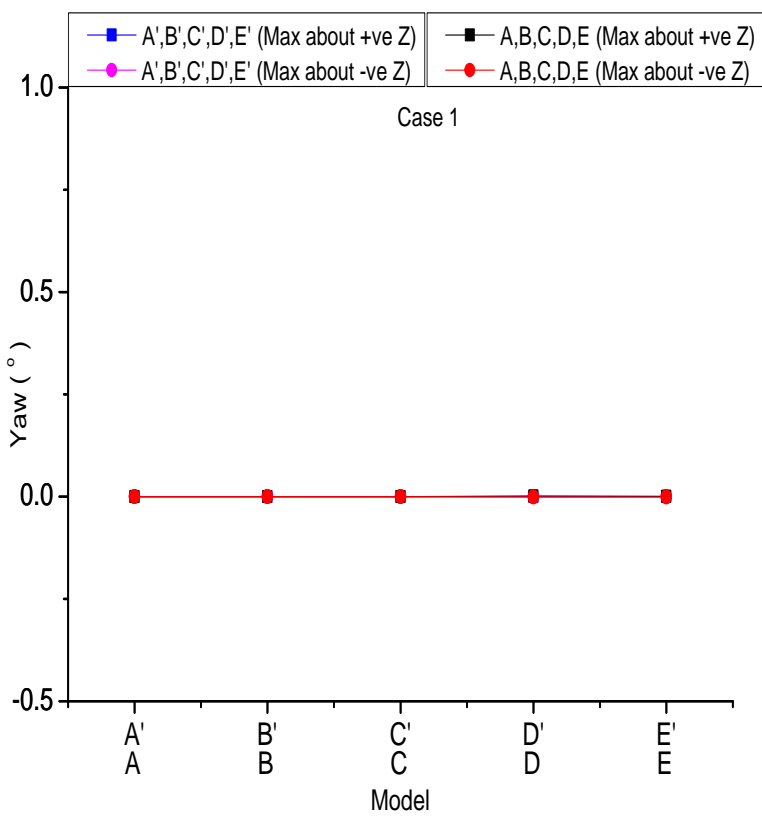

Fig -9a: Peak yaw response (case 1)

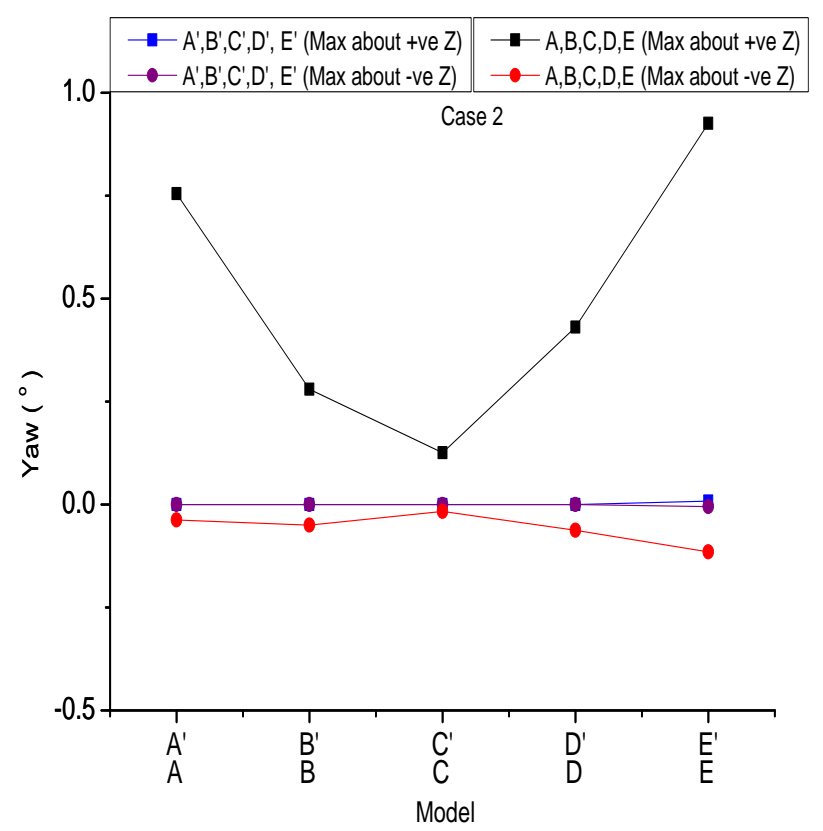

Fig -9b: Peak yaw response (case 2)

\section{CONCLUSION}

Hydrodynamic analysis was carried out to obtain effect of wind turbine tower TLP FOWT responses. It is observed that TLP FOWT has higher translational motions (surge, sway, and heave) as compared to rotational motions (roll, pitch, and yaw). The metacentric height improves drastically after adding weight to concrete ballast. Higher reserve buoyancy helps reduce surge, sway, roll and yaw. The direction of the incident wave and wind does not affect heave response and remains same when incident wave and wind acts at $0^{0}$ or $45^{\circ}$. Higher reserve buoyancy increases pitch response only when incident wave and wind is acting at $0^{0}$ but the reverse effect is observed when incident wave and wind is acting at $45^{\circ}$. 


\section{ACKNOWLEDGEMENTS}

I would like to thank Dr SWA Naqvi, Director, National Institute of Oceanography-Goa; Dr. Mohandas Chadaga, H.O.D. of Department of Civil Engineering at Manipal Institute of Technology, Manipal-Karnataka for giving me this opportunity to carry out research and last but not the least a special thanks to Mr. Pierpaolo Ricci from Global Maritime Consultancy, London (www.researchgate.net) who helped me to overcome critical difficulties.

\section{REFERENCES}

[1] MNRE. (2013, 15 June). National Offshore Wind Energy Policy [English]. Available: http://mnre.gov.in/file-manager/UserFiles/draftnational-policy-for-offshore-wind.pdf

[2] Henderson, C. Morgan, B. Smith, H. Sorensen, R. Barthlmie, and B. Boesmans, "Offshore Wind Energy in Europe - A Review of the State-of-the-art," Wind Energy, vol. 6, pp. 35-52, 2003.

[3] W. Musial and S. Butterfield. Future for Offshore Wind Energy in United States [Online]. Available: http://www.nrel.gov/docs/fy04osti/36313.pdf

[4] C. M. Wang, T. Utsunomiya, S. C. Wee, and Y. S. Choo, "Research of floating wind turbines: a literature survey," The IES Journal Part A: Civil \& Structural Engineering, vol. 3, pp. 267-277, 2010.

[5] J. Jonkman, S. Butterfield, W. Musial, and G. Scott, "Definition of a 5-MW Reference Wind Turbine for Offshore System Development," USA NREL/TP500-38060, 2009.

[6] J. E. Withee, "Fully Coupled Dynamic Analysis of a Floating Wind Turbine System," Ph.D., Naval Architecture and Marie Engineering, Massachusetts Institute of Technology, 2004

[7] K. H. Lee, "Response of Floating Wind Turbines to Wind and Wave Excitation," MS, Naval Architecture and Marine Engineering, Massachusetts Institute of Technology, 2005.

[8] E. N. Wayman, P. D. Sclavounos, S. Butterfield, J. Jonkman, and W. Musial, "Coupled Dynamic Modeling of Floating Wind Turbine System," presented at the Offshore Technology Conference, Houston, Texas, 2006.

[9] J. M. Jonkman, "Dynamic Modeling and Loads Analysis of an Offshore Floating Wind Turbine," National Renewable Energy Laboratory NREL/TP500-41958, 2007.

[10] D. Matha, "Model Development and Loads Analysis of an Offshore Wind Turbine on a Tension Leg Platform, with a Comparison to Other Floating Turbine Concepts," NREL/SR-500-45891, 2009.

[11] D. Matha, T. Fischer, M. Kuhn, and J. Jonkman, "Model Development and Loads Analysis of a Wind Turbine on a Floating Offshore Tension Leg Platform," presented at the European Offshore Wind Conference and Exhibition, Stockholm, Sweden, 2009.

[12] N. Robertson and J. M. Jonkman, "Loads Analysis of Several Offshore Floating Wind Turbine Concepts," presented at the International Society of Offshore and Polar Engineers, Maui, Hawaii, 2011

[13] H. Bagbanci, "Dynamic Analysis of Offshore Floating Wind Turbines," Naval Architecture and Marine Engineering, Technical University of Lisbon, 2011.

[14] Myhr and T. A. Nygaard, "Load Reductions and Optimizations on Tension-Leg-Buoy Offshore Wind Turbine Platforms," in International Offshore and Polar Engineering Conference, Rhodes, Greece, 2012

[15] D. S. B. Rao and R. P. Selvam, "Dynamic Time Domain Analysis of a Tension Based Tension Leg Platform (TBTLP) Under Irregular Waves," Journal of Information, Knowledge and Research In Mechanical Engineering, vol. 2, pp. 217-221, 2013.

[16] D. S. B. Rao, R. P. Selvam, and N. Srinivasan, "Response Analysis of Tension Based Tension Leg Platform Under Irregular Waves," in Indian National Conference on Harbour and Ocean Engineering, Goa, India, 2014, pp. 1-6

[17] Athanasia and A. B. Genachte, "Deep offshore and new foundation concepts," presented at the Deep Wind, Trondheim Norway, 2013.

[18] H. Wang and Y. Fan, "Preliminary Design of Offshore Wind Turbine Tension Leg Platform In South China Sea," Journal if Engineering Science and Technology Review, vol. 6, pp. 88-92, 2013.

[19] H. Wang, Y. Fan, and Y. Liu, "Dynamic Analysis of a Tension Leg Platform for Offshore Wind Turbines," Journal of Power Technology, vol. 94, pp. 42-49, 2014.

[20] E. E. Bachynski, "Design and Dynamic Analysis of Tension Leg Platform Wind Turbines," Ph.D., Department of Marine Technology, Norwegian University of Science and Technology, Norway, 2014

[21] "Design of Offshore Wind Turbine Standard," in DNV-OS-J101, ed: Det Norske Veritas, 2014.

[22] "Environmental Conditions and Environmental Loads," in DNV-RP-C205, ed: Det Norske Veritas, 2010

[23] R. Zhang, Y. Tang, J. Hu, S. Ruan, and C. Chen, "Dynamic response in frequency and time domains of a floating foundation for offshore wind turbines," Ocean Engineering, vol. 60, pp. 115-123, 2013

\section{BIOGRAPHIES}

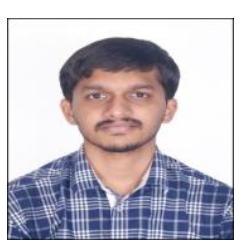

Yeshwant V. Prabhu Chodnekar is M.Tech Structural Engineering student at Manipal Institute of Technology, Manipal - Karnataka, India

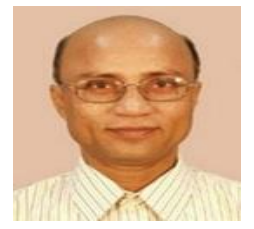

Dr. Sukomal Mandal is Retd. Chief Scientist \& Head of Ocean Engineering Division at CSIR - National Institute of Oceanography, Donapaula-Goa, India. $\mathrm{He}$ has research interest in design parameters for marine structures, 
coastal/ocean structures, neural networks in coastal/ocean engineering, ocean waves. He has several publication in national \& international journals.

Dr. Balakrishna Rao K. is Professor at Department of Civil Engineering, Manipal Institute of Technology, Manipal Karnataka, India. He has several publication in national \& international journals. 